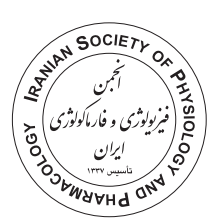

\title{
Protective effects of date palm pollen extract on gentamicin-induced hepatotoxicity
}

Zeynab Mohamadi Yarijani ${ }^{1,2}$, Seyed Hamid Madani ${ }^{3}$, Saeed Changizi-Ashtiyani ${ }^{4}$, Houshang Najafi ${ }^{1,2^{*}}$ (DD

1. Medical Biology Research Center, Kermanshah University of Medical Sciences, Kermanshah, Iran

2. Health Technology Institute, Kermanshah University of Medical Sciences, Kermanshah, Iran

3. Molecular Pathology Research Center, Imam Reza Hospital, Kermanshah University of Medical Sciences, Kermanshah, Iran

4. Department of Physiology, Faculty of Medicine, Arak University of Medical Sciences, Arak, Iran

\begin{abstract}
Introduction: Gentamicin, as an aminoglycoside antibiotic, is used to treat gram-negative bacterial infections. But despite its beneficial effects, gentamicin has side effects such as hepatotoxicity. Therefore, the aim of the present study was to investigate the protective effect of date palm pollen (DPP) hydroalcoholic extract against gentamicin-induced hepatotoxicity in rats.

Methods: In present study the animals were divided into 5 groups, including control, sham, gentamicin and the two groups of gentamicin plus DPP extract at $200 \mathrm{mg} / \mathrm{kg}$ and $400 \mathrm{mg} / \mathrm{kg}$. The plasma levels of aspartate aminotransferase (AST) and alanine aminotransferase (ALT) enzymes were measured to assess hepatic functional damages. Also, antioxidant enzymes activity including catalase (CAT) and superoxide dismutase (SOD) as well as total antioxidant capacity (FRAP) of the liver tissue sample were measured. Further, a tissue sample was fixed in 10\% formaldehyde for hematoxylin and eosin staining and histopathological study. In the end of experiment, the animals were euthanized by deep anesthesia.

Results: Gentamicin significantly increased the levels of plasma AST and ALT enzymes, caused histopathological damages, decreased CAT and SOD enzymes as well as FRAP in the liver tissue in comparison to the sham group. The concomitant administration of DPP hydroalcoholic extract and gentamicin with both examined doses could relatively improve these parameters, so that some parameters have not significant difference with the sham group.

Conclusion: It can be concluded that the hydroalcoholic extract of DPP reduces histopathological damages, oxidative stress as well as hepatic enzymes following their increase by gentamicin.
\end{abstract} Keywords: Gentamicin Date palm pollen Hepatotoxicity

Oxidative stress

\section{Introduction}

Aminoglycosides are a class of antibiotics formed by two or more amino-sugars and they are mainly used to treat infections caused by gram-negative bacteria (Randjelovic et al., 2017; Mahi-Birjand et al., 2020; Khaksari et al., 2019). The most widely used drug in this group is

\footnotetext{
* Corresponding author: Houshang Najafi, hnajafi@kums.ac.ir

Received 2 August 2020; Revised from 12 December 2020; Accepted 15 December 2020
}

Citation: Mohamadi Yarijani Z, Madani SH, Changizi-Ashtiyani S, Najafi H. Protective effects of date palm pollen extract on gentamicin-induced hepatotoxicity. Physiology and Pharmacology 2021; 25: 251-260. http://dx.doi.org/10.52547/ppj.25.3.251 
gentamicin (GM), which, despite its beneficial effects, causes hepatotoxicity (Noorani et al., 2011; Najafian et al., 2014; Yarijania et al., 2019).

The mechanism of GM-induced hepatotoxicity development is not yet known, but evidence suggests that GM stimulates oxidative stress and lipid peroxidation, production of reactive oxygen species (ROS) such as hydroxyl radical, hydrogen peroxide and superoxide anion (Najafian et al., 2014; Khan et al., 2011), leading to mitochondrial dysfunction (Ademiluyi et al., 2013) and decreases the activity of antioxidant enzymes such as catalase (CAT) and superoxide dismutase (SOD) (Khan et al., 2011; Ademiluyi et al., 2013). DNA damage, protein denaturation (Najafian et al., 2014), apoptosis and necrosis (Khaksari et al., 2019; Yarijania et al., 2019; Hafazeh et al., 2019), increased monocytes/macrophages infiltration (Yildirim et al., 2017), the release of pro-inflammatory cytokines and the activation of NF$\kappa \mathrm{B}$ are also among the other side effects associated with GM treatment (Yarijania et al., 2019). Numerous studies have shown that following the production of ROSs and the release of pro-inflammatory cytokines by gentamicin, the levels of hepatic alanine aminotransferase (ALT), aspartate aminotransferase (AST) and alkaline phosphatase (ALP) enzymes increase (Khaksari et al., 2019) and vascular congestion, cellular degeneration and sinusoidal dilation occur in the liver (Najafian et al., 2014; Yarijania et al., 2019).

Date palm pollen (DPP), with the scientific name of Phoenix dactylifera $\mathrm{L}$. is a soft powder among the palm tree branches that is consumed orally for various therapeutic purposes (Rasouli et al., 2018). Phytochemical studies have shown that DPP contains a very wide range of biochemical and nutritional substances, such as some essential and non-essential amino acids, trace elements, fatty acids as well as important flavonoids such as rutin, quercetin, luteolin-7-O-glucoside, apigenin, isohamnetin-3-O-glucoside and naringin depending on the species (El-Kashlan et al., 2015). DPP also contains minerals (cobalt, magnesium, copper, iron, selenium, zinc, boron and nickel), vitamins (A, C and E) and steroid compounds such as estradiol, estriol and estrone, which can be used to treat infertility (El-Kashlan et al., 2015; Hassan, 2011). Besides, it has been reported that DPP is a good source of natural antioxidants (Iftikhar et al., 2014). Many studies have shown that DPP has several effects such as reducing the expression of inflammato- ry cytokines such as IL-6, IL-8 and TNF- $\alpha$ as well as anti-inflammatory (Elberry et al., 2011), antioxidant (Abbas and Ateya, 2011), anticoccidial, anti-apoptosis (Metwaly et al., 2014), anti-angiogenesis (Rasouli et al., 2018) and hypoglycemic (Mohamed et al., 2018) effects. Other studies have reported that DPP hydroalcoholic extract reduces cadmium-induced toxicity in the testicles (El-Neweshy et al., 2013) and protects the liver in old animals (Uzbekova et al., 2003).

Since ancient times, medicinal plants have been commonly used to treat many diseases. Nowadays the use of herbal supplements, due to their numerous properties and fewer side effects, has a special important in the treatment of liver diseases. Due to its variety of phytochemical elements, DPP has many properties, including antioxidant and anti-inflammation. Therefore, the present study aimed to investigate the effect of DPP hydroalcoholic extract on GM-induced hepatotoxicity through measuring the histopathological damages, hepatic functional enzymes and oxidative stress.

\section{Materials and methods}

\section{Preparation and extraction of DPP}

Date palm pollen was prepared from a medicinal plant store (Ahvaz-Iran) and its accuracy was confirmed by a specialist in medicinal plants. In order to prepare DPP extract, 20g of DPP powder was added to one liter of $70 \%$ ethanol and placed on the shaker for $24 \mathrm{~h}$ in a dark environment. It was then centrifuged at 3000rpm for $10 \mathrm{~min}$ and the supernatant was separated. The supernatant portion was filtered and dried by a rotary evaporator at $40^{\circ} \mathrm{C}$ and stored at $-20^{\circ} \mathrm{C}$, away from light, until use (Yarijani et al., 2018; Najafi et al., 2017).

\section{Phytochemical analysis of the crude extract}

The phytochemical analysis was performed according to standard methods (Mohan and Gupta, 2017; Yarijania et al., 2019) to evaluate and determine the presence of alkaloids, tannins, flavonoids, saponins, triterpenoids, sterols, anthraquinones, anthocyanins, coumarins and musilage in DPP hydroalcoholic extract. Any precipitation or change of color was considered as a positive response indicator. The results of the phytochemical analysis of DPP extract are presented in Table 1.

\section{Studied animals}

Current experiment was performed on 35 male Wis- 
TABLE 1: Phytochemical analyses of the hydroethanolic extract of date palm pollen.

\begin{tabular}{|lll|}
\hline Phytochemical Constituents & Test & Result \\
\hline Alkaloids & Wagner & + \\
& Dragendorff & ++ \\
& Tannic acid & ++ \\
\hline Tannins & $\mathrm{FeCl}_{3}$ & - \\
\hline Flavonoids & $5 \% \mathrm{HCl}$ in $\mathrm{n}-\mathrm{Butanol}$ & ++++ \\
\hline Saponins & Shinoda & - \\
\hline Triterpenoids & Foam height & ++++ \\
\hline Musilage & Salkowski & - \\
\hline Sterols & Precipitation by ethanol & +++ \\
\hline Coumarins & Liebermann-Burchard & + \\
\hline Anthraquinones & $10 \% \mathrm{NaOH}$ & + \\
\hline Anthocyanins & $5 \% \mathrm{Ethanolic} \mathrm{KOH}$ & - \\
\hline
\end{tabular}

Phytochemical screening of date palm pollen extract for detecting different plant metabolites. (-) for absence, $( \pm)$ doubtful, $(+)$ positivity, $(++)$ strong positivity, $(+++)$ very strong positivity, and $(++++)$ indicates cases with maximum reaction.

tar rats ranging 200-250g body weight, which were obtained from the Laboratory Animal Breeding Center of Kermanshah University of Medical Sciences. The animals were kept at a temperature of $23 \pm 2^{\circ} \mathrm{C}$ in a 12 -hour light/dark cycle and had free access to standard food and tap water throughout the experiment. As a rule and to minimize the pain and suffering of studied animals, rats with abnormal symptoms would have been excluded from the study and euthanized by deep anesthesia. Ethical principles of working with laboratory animals were followed strongly according to the European Economic Community Guidelines for the care and use of laboratory animals (EEC Directive of 1986; 86/609/ EEC) and the ethics committee of Kermanshah University of Medical Sciences approval (Approval number: IR.KUMS.REC.1398.961).

\section{Experimental treatments}

To carry out the study, the animals were randomly divided into 5 groups $(n=7)$. The study period lasted for 9 days and different parameters were measured on the tenth day. The first group (control) did not receive any extract solvent (containing 2\% Tween 80 in normal saline), extract, or gentamicin during the study period. The second group (sham) received an intraperitoneal injection of extract solvent for 9 days and from the third day, normal saline was injected instead of gentamicin. The third group was gentamicin, which received gentamicin at a dosage of $100 \mathrm{mg} / \mathrm{kg}$ intraperitoneally from the third to the ninth day. In this group, the extract solvent was injected from the beginning to the end of the treatment period. The fourth (GM+DPP200) and the fifth (GM+DPP400) groups received an intraperitoneal injection of DPP extract for 9 consecutive days at dosages of 200 or $400 \mathrm{mg} / \mathrm{kg}$, respectively, and GM was injected from the third to the ninth day. At the end of the study period, sodium pentobarbital $(55 \mathrm{mg} / \mathrm{kg})$ was used to anesthetize the studied animals, followed by making an incision in the linea alba. A blood sample was then taken from the abdominal aorta and its plasma was isolated and stored at $-72^{\circ} \mathrm{C}$ for hepatic enzymes measurements (Yarijania et al., 2019; Mohammadi et al., 2019). A sample of liver tissue was immediately frozen in liquid nitrogen to measure tissue Ferric Reducing/Antioxidant Power (FRAP) level, CAT and SOD activities. By the way a sample of liver tissue was fixed in $10 \%$ formaldehyde solution for histological study (Yarijania et al., 2018; Yarijania et al., 2019). 


\section{Measurement of biochemical parameters}

To evaluate hepatic functional disturbances, an Auto-Analyzer was used to measure the ALT and AST enzymes.

\section{Measurement of oxidative stress}

To evaluate the amount of antioxidant enzymes in the liver tissue, the activity of CAT and SOD enzymes was evaluated by colorimetric assay using a commercial kit (Kiazist, Iran) based on the manufacturer's protocol. The FRAP level, as indication of tissue total antioxidant capacity, was evaluated based on Benzie method (Benzie and Strain, 1999; Mohammadi et al., 2019).

\section{Measurement of hepatic tissue damages}

To assess hepatic tissue damages, tissue sections with $5 \mu \mathrm{m}$ thickness were prepared and stained with hematoxylin-eosin. Thereafter slides were graded using a light microscope. Each slide were scored based on the rate of leukocyte infiltration, cell degeneration, sinusoidal dilatation and vascular congestion which measured and graded in 10 different areas under microscope, so that lack of any damage received grade $0,1-20 \%$ damages grade $1,21-40 \%$ damages grade $2,41-60 \%$ damages grade 3, $61-80 \%$ damages grade 4 and $81-100 \%$ damages grade 5 . Then, the total histopathologic score, which was equal to the sum of all grades of the different damages, was calculated and analyzed. (Najafi et al., 2017; Yarijani et al., 2018; Mohammadi et al., 2019).

\section{Statistical analysis}

For data analysis, SPSS-23 software was used, and all data were presented as mean \pm SEM. In order to compare data on hepatic enzymes as well as oxidative stress, Oneway analysis of variance (ANOVA) and Duncan's post hoc test were used. The non-parametric Kruskal-Wallis and Mann-Whitney tests were also used to analyze the total histopathological score. The level of statistical significance was set at $\mathrm{P}<0.05$.

\section{Results}

The effect of DPP extract on hepatic enzymes

A

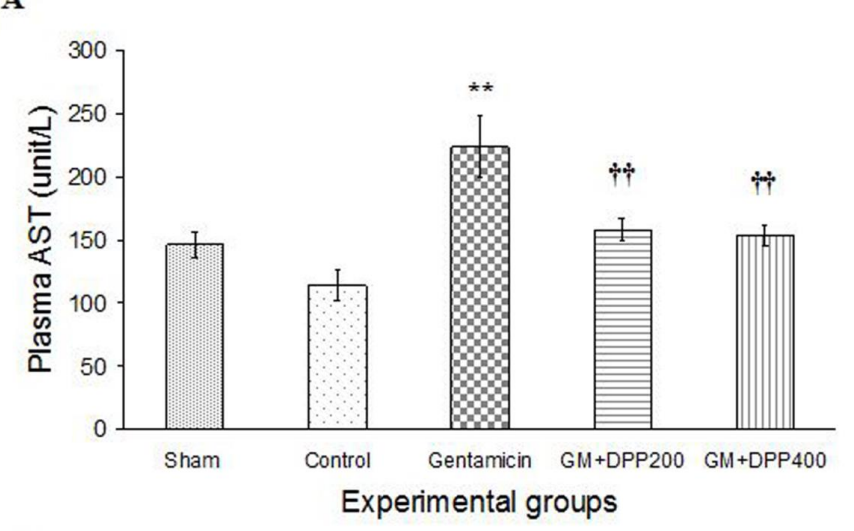

B

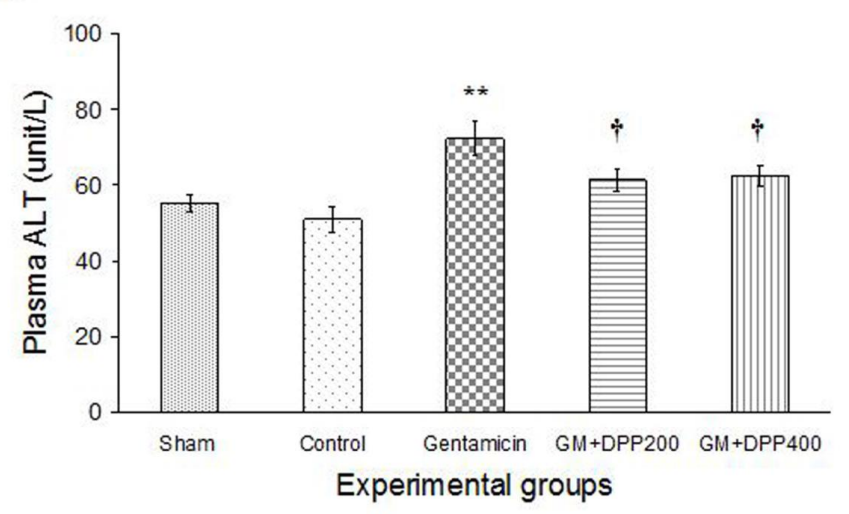

FIGURE 1. Mean \pm SEM for A: Plasma aspartate aminotransferase (AST) and B: alanine aminotransferase (ALT) enzymes activity in rats without any intervention (Control), received normal saline (sham), gentamicin, and gentamicin plus date palm pollen extract at 200 or 400 $\mathrm{mg} / \mathrm{kg}\left(\mathrm{GM}+\mathrm{DPP} 200\right.$ and GM+DPP400)(n=7). ${ }^{* *} P<0.01$ in comparison with the sham group; ${ }^{\dagger} P<0.05$ and ${ }^{\dagger} P<0.01$ in comparison with the gentamicin group. 


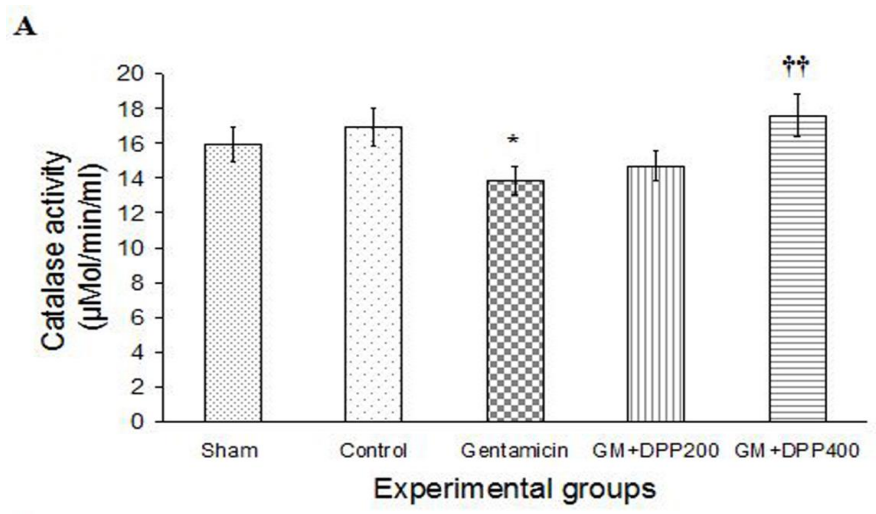

B

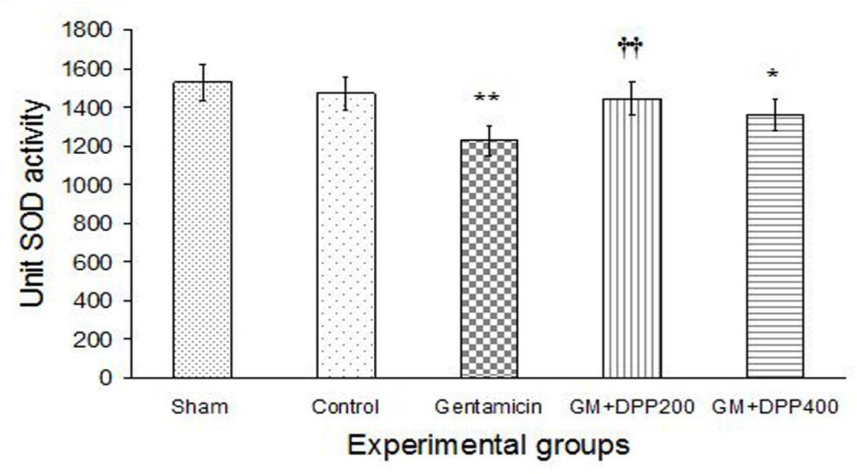

FIGURE 2. A: Hepatic tissue catalase and B: superoxide dismutase (SOD) activity in rats without any intervention (Control), received normal saline (sham), gentamicin and gentamicin plus date palm pollen extract at 200 or $400 \mathrm{mg} / \mathrm{kg}$ (GM+DPP200 and GM+DPP400). Data is shown as mean $\pm \operatorname{SEM}(\mathrm{n}=7) .{ }^{*} P<0.05$ and $^{* *} P<0.01$ in comparison with the sham group; ${ }^{\dagger} P<0.01$ in comparison with the gentamicin group.

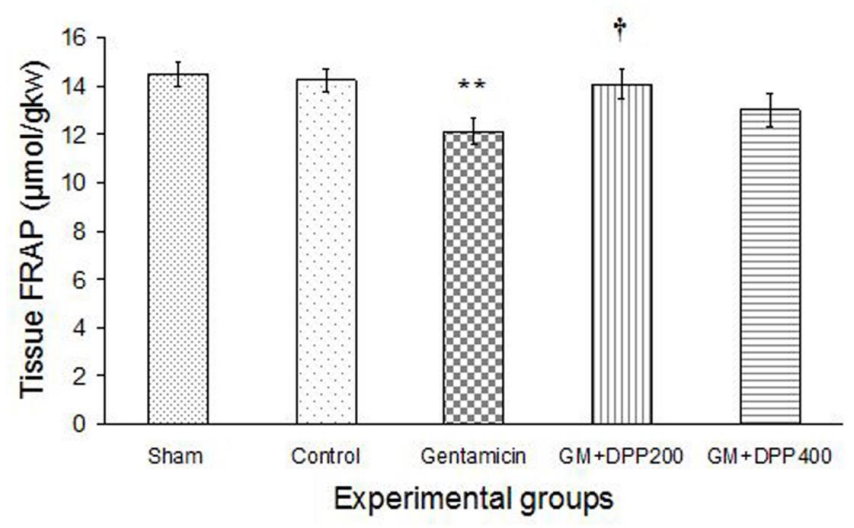

FIGURE 3. Hepatic tissue total antioxidant capacity (FRAP) in rats without any intervention (Control), received normal saline (sham), gentamicin, and gentamicin plus date palm pollen extract at 200 or $400 \mathrm{mg} / \mathrm{kg}(\mathrm{GM}+\mathrm{DPP} 200$ and $\mathrm{GM}+\mathrm{DPP} 400)$. Data is presented as mean $\pm \mathrm{SEM}$ $(\mathrm{n}=7) .{ }^{* *} P<0.01$ in comparison with the sham group; ${ }^{\dagger} P<0.05$ in comparison with the gentamicin group.

As demonstrated in Figure 1, the level of AST and ALT enzymes in the sham group did not differ significantly from those in the control one. Gentamicin administration increased AST and ALT level as compared to the sham group $(P<0.01)$. The concomitant use of GM and DPP extract with both examined doses could significantly reduce AST $(P<0.01)$ and ALT $(P<0.05)$ level as compared to the GM group and not significantly differ with the sham group.

\section{The effect of DPP extract on hepatic oxidative stress}

As shown in Figure 2, CAT and SOD activity in the liver tissue of the sham group did not differ to the control. Administration of GM reduced the activity of both CAT $(P<0.05)$ and SOD $(P<0.01)$ enzymes in the liver tissue compared to their levels in the sham group. The use of DPP extract at $400 \mathrm{mg} / \mathrm{kg}$ could significantly increase CAT activity as compared to the GM group $(P<0.01)$, so that it reached the same level as the sham group. Moreover, the concomitant administration of 
TABLE 2: The effect of DPP extract on hepatic histopathological damages induced by gentamicin administration.

\begin{tabular}{lccccc} 
Histopathologic damages & \multicolumn{3}{c}{ Experimental groups } \\
& Sham & Control & GM & GM+DPP200 & GM+DPP400 \\
\hline Leukocytes infiltration & 0 & 0 & 2.8 & 0.3 & 0.6 \\
Cellular degeneration & 0 & 0 & 3.2 & 1.8 & 2.1 \\
Sinusoidal dilatation & 0 & 0 & 3.9 & 1.1 & 1.2 \\
Vascular congestion & 0.6 & 0 & 4.8 & 1.4 & 1.6 \\
Total histopathologic score & 0.6 & 0 & 14.7 & $+\dagger^{*}$ & $\dagger^{*}$
\end{tabular}

Histopathological scores in rats without any intervention (control), received normal saline (sham), gentamicin (GM), or gentamicin plus date palm pollen extract at 200 or $400 \mathrm{mg} / \mathrm{kg}$ (GM+DPP200 and GM+DPP400) body weight. ${ }^{*} P<0.05$ and ${ }^{* * *} P<0.001$, in comparison with sham group. ${ }^{\Uparrow} P<0.01$, in comparison with gentamicin group.
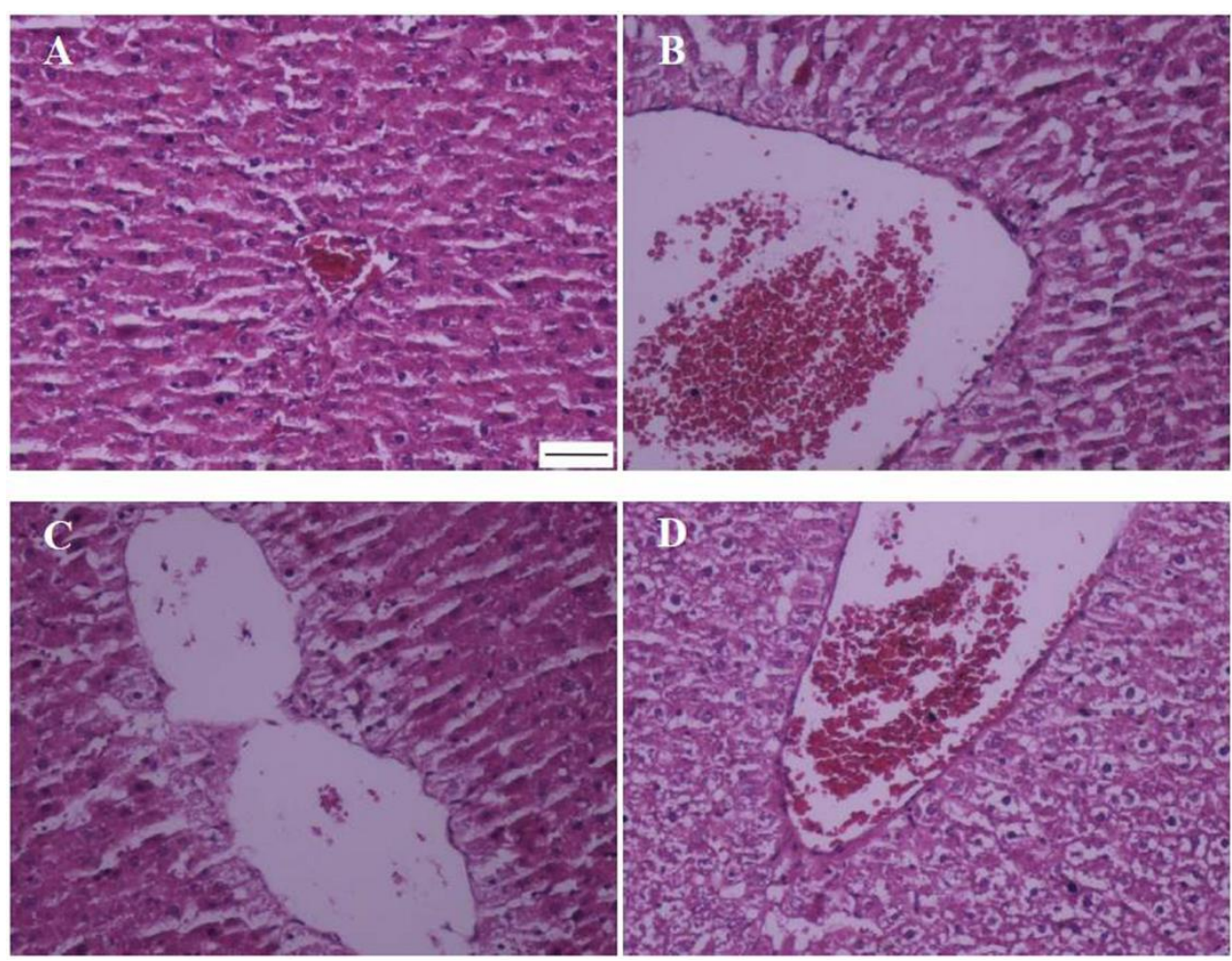

FIGURE 4. Representing histopathological alterations in liver tissue of normal saline receiving group (A), gentamicin (B) and gentamicin plus date palm pollen extract at 200 (C) or 400 mg/kg (D). Haematoxylin-Eosin staining, magnification 200x, scale bar: $100 \mu \mathrm{m}$.

GM and DPP extract at $200 \mathrm{mg} / \mathrm{kg}$ could increase SOD activity $(P<0.01)$, so that it has not significant difference with the sham group. Besides, GM reduced the FRAP level in the liver tissue in comparison to the sham group $(P<0.01)$, and the DPP extract at $200 \mathrm{mg} / \mathrm{kg}$ could correct it and brought it to the same level as in the sham group $(P<0.05$, Figure 3).

\section{The effect of DPP extract on hepatic histopathological damages}

Hepatic histopathological damages induced by genta- micin are shown in Figure 4 and their grades are represented in Table 2. Gentamicin led to leukocyte infiltration, cell degeneration, sinusoidal dilatation and vascular congestion, so that the total histopathologic score in the GM group reached 14.7, which was significantly higher than the sham group. The use of DPP extract reduced these damages in both GM+DPP200 and GM+DPP400 groups, so that the total histopathological score in the two doses of 200 and $400 \mathrm{mg} / \mathrm{kg}$ reached 4.6 and 5.5 , respectively, which was significantly lower than the GM group $(P<0.01)$. But they were still higher than their val- 
ues in the sham group $(P<0.05)$.

\section{Discussion}

Gentamicin is widely used to treat gram-negative bacteria induced infections; however, its usage is limited due to its serious side effects such as hepatotoxicity and nephrotoxicity. To reduce the toxicity induced by GM, using herbal supplements and treatments are common around the world. Current study showed that gentamicin increased the plasma levels of AST and ALT enzymes, as well as leukocyte infiltration, cell degeneration, sinusoidal dilatation and vascular congestion in the liver tissue and decreased the activity of SOD and CAT antioxidant enzymes and the FRAP level of the liver tissue. The results of this study, for the first time, demonstrated that DPP hydroalcoholic extract can moderate gentamicin negative effects. It was clearly evident that all the damages observed are due to GM, because the values of the measured parameters in the sham group have not significant difference with those in the control one.

Our results demonstrated that the use of GM increased the levels of AST and ALT enzymes. It has been shown that an increase in hepatic enzymes indicates damage to hepatic cells (Najafian et al., 2014). Numerous studies have shown that GM produces ROS by inducing oxidative stress (Rasouli et al., 2018; Galaly et al., 2014; Yarijani et al., 2016). The most important effect of ROS is their reaction with membrane lipids and their peroxidation, which in turn increases the permeability of the membrane and disrupts its integrity (Sultana et al., 2012). Following an increase in membrane permeability and disruption of plasma membrane integrity in hepatic cells, hepatic enzymes that are naturally present in the cytosol enter the blood stream and increase the levels of hepatic enzymes (Khan et al., 2011). Therefore, one of the reasons for the increase in hepatic enzymes following GM administration is cellular damage by ROS, which is confirmed by the results of the present study as well. On the other hand, it has been shown that GM-induced nephrotoxicity can also affect the liver (Doi and Rabb, 2016; Gardner et al., 2016). Different studies suggested that uremic toxins, inflammatory mediators, activated leukocytes and oxidative stress are involved in hepatic damages induced by renal failure (Lee et al., 2018; Doi and Rabb, 2016). Therefore, part of the GM-induced hepatic damages may be due to its direct effects and the other part may be due to the GM-induced nephrotox- icity and its effect on the liver. It has been shown that the improvement of renal damages also leads to partial or complete improvement of hepatic damages as well (Mohammadi et al., 2019; Yarijania et al., 2019).

Comparing the results of DPP extract recipient groups with the GM group showed that the two examined doses of the extract could improve the levels of AST and ALT liver enzymes. In a study, Daoud et al. (2017) showed that DPP extract inhibited the release of cardiac enzymes by maintaining the integrity of cell membranes. Besides, in their study, Khan et al. (2011) showed that flavonoids prevented the production of free radicals due to their antioxidant properties as well as their capability for the inhibition of many enzymes. Another study has shown that alkaloids, due to their antioxidant properties, protect the liver and kidneys against GM (Khaksari et al., 2019). The results of the phytochemical study of the present study showed that DPP hydroalcoholic extract contained flavonoids, alkaloids, triterpenoids, coumarins and sterols (Table 1). Therefore, it can be concluded that DPP extract due to its chemical compounds, which have antioxidant properties, neutralizes free radicals, maintains the integrity of cell membranes and thus reduces the levels of AST and ALT enzymes.

The results of the present study showed that GM decreased CAT, SOD and FRAP levels in the liver tissue in comparison to the sham, which indicates the occurrence of oxidative stress in GM receiving group. This finding is in line with the results of many studies that have shown that GM reduces the activity of antioxidant enzymes (Ademiluyi et al., 2013; Galaly et al., 2014; Yarijania et al., 2019). When ROS production increases or tissue antioxidant defenses decrease, oxidative stress occurs (Ademiluyi et al., 2013; Valko et al., 2007). GM has been shown to inhibit electron transfer and stimulate the production of ROS, such as hydrogen peroxide, superoxide anion and hydroxyl radical by destruction of lysosomes and damaging other organs, including mitochondria (Mahmoud, 2017). The ROS also damage cellular proteins and nucleic acids and lead to the peroxidation of cell membrane lipids and their subsequent instability (Katary and Salahuddin, 2017; Martinez-Salgado et al., 2004). Moreover, GM also increases inducible nitric oxide synthase (iNOS) expression and the resulting nitric oxide combines with ROS and leads to nitrosative stress that is much stronger than ROS (Mahmoud et al., 2014). Cells, on the other hand, have an antioxidant de- 
fense mechanism that scavenges free radicals. GM has been shown to reduce the antioxidant reserves of cells, and the higher the degree of damage, the greater the rate of discharge (Manikandan et al., 2011). In the present study, CAT and SOD activities and the FRAP level of the liver tissue in the GM group reduced. Therefore, GM both directly induces oxidative and nitrosative stress and reduces the antioxidant reserves of cells.

Co-administration of DPP extract with GM increased CAT, SOD and FRAP levels in the liver tissue. This finding is in line with the results of previous studies showing that DPP extract has antioxidant property and scavenging activity of free radicals and also reduces iNOS activity and nitric oxide levels (El-Kashlan et al., 2015; Abbas and Ateya, 2011; El-Neweshy et al., 2013). Therefore, DPP extract has ROS scavenging activity and also interferes with the pathway of free radicals production. The antioxidant property of DPP extract can be due to its flavonoids as well as its vitamins (A, C and E). In the phytochemical analysis, our studied extract was also at the highest level of flavonoids.

The present study showed that pre-treatment with DPP hydroalcoholic extract improved hepatic histopathologic damages induced by GM. As mentioned earlier, gentamicin destroys cell membranes by inducing oxidative stress, thereby increasing hepatic enzymes. Pre-treatment with DPP extract has significantly reduced oxidative stress indicators, resulting in reduced histopathologic damages and hepatic enzymes. Therefore, DPP extract has been shown to reduce hepatic cell damages by reducing cellular damaging parameters, which in this study is expressed as reduced leukocyte infiltration, cell degeneration, sinusoidal dilatation and vascular congestion.

\section{Conclusion}

In conclusion, administration of DPP hydroalcoholic extract reduces GM-induced increases in hepatic enzymes, histopathological damages and oxidative stress in the liver tissue. The mechanism of this protective effect of DPP may be through the reduction of oxidative stress or other pathways that require further study.

\section{Acknowledgements}

The authors gratefully acknowledge the research deputy of Kermanshah University of medical sciences for financial support (Research project 980921 to $\mathrm{HN}$ ).

\section{Conflict of interest}

There are no conflicts of interest.

\section{References}

Abbas FA, Ateya AM. Estradiol, esteriol, estrone and novel flavonoids from date palm pollen. Aust J Basic Appl Sci 2011; 5: 606-14.

Ademiluyi AO, Oboh G, Owoloye TR, Agbebi OJ. Modulatory effects of dietary inclusion of garlic (Allium sativum) on gentamycin-induced hepatotoxicity and oxidative stress in rats. Asian Pac J Trop Biomed 2013; 3: 470-5. https://doi. org/10.1016/S2221-1691(13)60098-2

Benzie IF, Strain JJ. Ferric reducing/antioxidant power assay: Direct measure of total antioxidant activity of biological fluids and modified version for simultaneous measurement of total antioxidant power and ascorbic acid concentration. Methods Enzymol 1999; 299: 15-27. https://doi. org/10.1016/S0076-6879(99)99005-5

Daoud A, Mnafgui K, Turki M, Jmal S, Ayadi F, ElFeki A, et al. Cardiopreventive effect of ethanolic extract of Date Palm Pollen against isoproterenol induced myocardial infarction in rats through the inhibition of the angiotensin-converting enzyme. Exp Toxicol Pathol 2017; 69: 656-65. https://doi. org/10.1016/j.etp.2017.06.004

Doi K, Rabb H. Impact of acute kidney injury on distant organ function: recent findings and potential therapeutic targets. Kidney Int 2016; 89: 555-64. https://doi.org/10.1016/j. kint.2015.11.019

Elberry AA, Mufti ST, Al-Maghrabi JA, Abdel-Sattar EA, Ashour OM, Ghareib SA, et al. Anti-inflammatory and antiproliferative activities of date palm pollen (Phoenix dactylifera) on experimentally-induced atypical prostatic hyperplasia in rats. J Inflamm 2011; 8: 1-3. https://doi. org/10.1186/1476-9255-8-40

El-Kashlan AM, Nooh MM, Hassan WA, Risk SM. Therapeutic potential of date palm pollen for testicular dysfunction induced by thyroid disorders in male rats. PLoS One 2015; 10: e0139493. https://doi.org/10.1371/journal. pone. 0139493

El-Neweshy M, El-Maddawy Z, El-Sayed YJA. Therapeutic effects of date palm (P hoenix dactylifera L.) pollen extract on cadmium-induced testicular toxicity. Andrologia 2013; 45: 369-78. https://doi.org/10.1111/and.12025

Galaly SR, Ahmed OM, Mahmoud AM. Thymoquinone and curcumin prevent gentamicin-induced liver injury by attenuating oxidative stress, inflammation and apoptosis. J Physiol Pharmacol 2014; 65: 823-32. 
Gardner DS, Brot SD, Dunford LJ, Roma LG, Welham SJM, Fallman R, et al. Remote effects of acute kidney injury in a porcine model. Am J Physiol Renal Physiol 2016; 310: F259-71. https://doi.org/10.1152/ajprenal.00389.2015

Hafazeh L, Changizi-Ashtiyani S, Jalali-Mashayekhi F, Rahjo T, Najafi H, Babaei S. The therapeutic effect of Centella asiatica hydroalcoholic extract on gentamicin-induced nephrotoxicity. Physiol Pharmacol 2019; 23: 215-23.

Hassan HM. Chemical composition and nutritional value of palm pollen grains. Glob J Biotech Biochem 2011; 6: 1-7.

Iftikhar S, Ahmad M, Aslam HM, Saeed T, Arfat Y. Evaluation of spermatogenesis in prepubertal albino rats with date palm pollen supplement. Afr J Pharm Pharmacol 2014; 8: 59-65. https://doi.org/10.5897/AJPP2013.3662

Katary M, Salahuddin A. Ameliorative effect of gossypin against gentamicin-induced nephrotoxicity in rats. Life Sci 2017; 176: 75-81. https://doi.org/10.1016/j.lfs.2017.03.009

Khaksari M, Esmaili S, Abedloo R, Khastar H. Palmatine ameliorates nephrotoxicity and hepatotoxicity induced by gentamicin in rats. Arch Physiol Biochem 2019; 26: 1-6. https://doi.org/10.1080/13813455.2019.1633354

Khan MR, Badar I, Siddiquah A. Prevention of hepatorenal toxicity with sonchus asper in gentamicin treated rats. BMC Complement Altern Med 2011; 11: 1-9. https://doi. org/10.1186/1472-6882-11-113

Lee SA, Cozzi M, Bush EL, Rabb H. Distant organ dysfunction in acute kidney injury: a review. Am J Kidney Dis 2018; 72: 846-56. https://doi.org/10.1053/j.ajkd.2018.03.028

Mahi-Birjand M, Yaghoubi S, Abdollahpour-Alitappeh M, Keshtkaran Z, Bagheri N, Pirouzi A, et al. Protective effects of pharmacological agents against aminoglycoside-induced nephrotoxicity: a systematic review. Expert Opin Drug Saf 2020; 19: 167-86. https://doi.org/10.1080/14740338.2020. 1712357

Mahmoud AM, Ahmed OM, Galaly SR. Thymoquinone and curcumin attenuate gentamicin-induced renal oxidative stress, inflammation and apoptosis in rats. EXCLI J 2014; 13: 98-110.

Mahmoud YI. Kiwi fruit (Actinidia deliciosa) ameliorates gentamicin-induced nephrotoxicity in albino mice via the activation of Nrf2 and the inhibition of NF-kB (Kiwi \& gentamicin-induced nephrotoxicity). Biomed Pharmacother 2017; 94: 206-18. https://doi.org/10.1016/j.biopha.2017.07.079

Manikandan R, Beulaja M, Thiagarajan R, Priyadarsini A, Saravanan R, Arumugam M. Ameliorative effects of curcumin against renal injuries mediated by inducible nitric oxide synthase and nuclear factor kappa B during gentamicin-induced toxicity in Wistar rats. Eu J Pharmacol 2011; 670: 578-85. https://doi.org/10.1016/j.ejphar.2011.08.037

Martinez-Salgado C, Eleno N, Morales AI, Perez-Barriocanal F, Arevalo M, Lopez-Novoa JM. Gentamicin treatment induces simultaneous mesangial proliferation and apoptosis in rats. Kidney Int 2004; 65: 2161-71. https://doi. org/10.1111/j.1523-1755.2004.00642.x

Metwaly MS, Dkhil MA, Al-Quraishy S. Anti-coccidial and anti-apoptotic activities of palm pollen grains on Eimeria papillata-induced infection in mice. Biologia 2014: 69: 254-9. https://doi.org/10.2478/s11756-013-0297-9

Mohammadi M, Najafi H, Yarijani ZM, Vaezi G, Hojati V. Piperine pretreatment attenuates renal ischemia-reperfusion induced liver injury. Heliyon 2019; 5: e02180. https://doi. org/10.1016/j.heliyon.2019.e02180

Mohamed NA, Ahmed OM, Hozayen WG, Ahmed MA. Ameliorative effects of bee pollen and date palm pollen on the glycemic state and male sexual dysfunctions in streptozotocin-Induced diabetic wistar rats. Biomed Pharmacother 2018; 97: 9-18. https://doi.org/10.1016/j.biopha.2017.10.117

Mohan S, Gupta D. Phytochemical analysis and differential in vitro cytotoxicity assessment of root extracts of inula racemosa. Biomed Pharmacother 2017; 89: 781-95. https://doi. org/10.1016/j.biopha.2017.02.053

Najafi H, Mohamadi Yarijani Z, Changizi-Ashtiyani S, Mansouri K, Modarresi M, Madani SH, et al. Protective effect of malva sylvestris L. extract in ischemia-reperfusion induced acute kidney and remote liver injury. PLoS One 2017; 12: e0188270. https://doi.org/10.1371/journal.pone.0188270

Najafian M, Mokaber H, Pourahmadi M, Farzam M, Kargar Jahromi H. Pathological changes of gentamicin in liver tissue and antioxidant property of Cinnamon extract on wistar rats. Biochem Pharmacol 2014; 7: 341-7. https://doi. org/10.13005/bpj/496

Noorani AA, Gupta K, Bhadada K, Kale MK. Protective effect of methanolic leaf extract of Caesalpinia Bonduc on gentamicin-induced hepatotoxicity and nephrotoxicity in rats. Iran J Pharmacol Ther 2011; 10: 21-5.

Randjelovic P, Veljkovic S, Stojiljkovic N, Sokolovic D, Ilic I. Gentamicin nephrotoxicity in animals: current knowledge and future perspectives. EXCLI J 2017; 16: 388-99.

Rasouli H, Norooznezhad AH, Rashidi T, Hoseinkhani Z, Mahnam A, Tarlan M, et al. Comparative in vitro/theoretical studies on the anti-angiogenic activity of date pollen hydro-alcoholic extract: highlighting the important roles of 
its hot polyphenols. Bio Impacts 2018; 8: 281-94. https:// doi.org/10.15171/bi.2018.31

Sultana N, Shimmi SC, Parash MT, Akhtar J. Effects of ashwagandha (Withania somnifera) root extract on some serum liver marker enzymes (AST, ALT) in gentamicin intoxicated rats. J Bangladesh Soc Physiol 2012; 7: 1-7. https://doi. org/10.3329/jbsp.v7i1.11152

Uzbekova DG, Makarova VG, Khvoynitskaya LG, Slepnev AA. Evaluation of bee collected pollen influence on lipid peroxidation, antioxidant system and liver function in old animals. J Hepatol 2003; 38: 203-8. https://doi.org/10.1016/ S0168-8278(03)80078-8

Valko M, Leibfritz D, Moncol J, Cronin MT, Mazur M, Telser J. Free radicals and antioxidants in normal physiological functions and human disease. Int J Biochem Cell Biol 2007; 39: 44-84. https://doi.org/10.1016/j.biocel.2006.07.001

Yarijani ZM, Godini A, Madani SH, Najafi H. Reduction of cisplatin induced renal and hepatic side effects in rat through antioxidative and anti-inflammatory properties of Malva sylvestris L. extract. Biomed Pharmacother 2018; 106: 1767-74. https://doi.org/10.1016/j.biopha.2018.07.115 Yarijani ZM, Najafi H, Madani,SH. Protective effect of crocin on gentamicin-induced nephrotoxicity in rats. Iran J Basic Med Sci 2016; 19: 337-43. https://www.ncbi.nlm.nih.gov/ pmc/articles/PMC4834125/

Yarijani ZM, Najafi H, Shackebaei D, Madani SH, Modarresi M, Jassemi SV. Amelioration of renal and hepatic function, oxidative stress, inflammation and histopathologic damages by Malva sylvestris extract in gentamicin induced renal toxicity. Biomed Pharmacother 2019; 112: 108635. https:// doi.org/10.1016/j.biopha.2019.108635

Yildirim BA, Kordali S, Kapakin KA, Yildirim F, Senocak EA, Altun S. Effect of Helichrysum plicatum DC. subsp. plicatum ethanol extract on gentamicin-induced nephrotoxicity in rats. J Zhejiang Univ Sci B 2017; 18: 501-11. https://doi.org/10.1631/jzus.B1500291 